\title{
INCREASED VASCULAR ENDOTHELIAL GROWTH FACTOR AND VASCULAR ENDOTHELIAL GROWTH FACTOR-C AND DECREASED NM23 EXPRESSION ASSOCIATED WITH MICRODISSEMINATION IN THE LYMPH NODES IN STAGE I NON-SMALL CELL LUNG CANCER
}

Yasuhiko Ohta, MD

Hiroshi Nozawa, MD

Yoko Tanaka, $\mathrm{PhD}$

Makoto Oda, MD

Yoh Watanabe, MD, FAATS
Objective: We examined a microdissemination of cancer cells in lymph nodes and assessed its clinical and biologic characteristics.

Methods: Both primary tumors and lymph nodes (2030 nodes) were obtained from 122 patients with primary stage I lung cancer who underwent curative operations with routine systematic nodal dissection of both the hilar and the mediastinal nodes. Immunohistochemical anticytokeratin staining was used to detect nodal microdissemination of cancer cells. Vascular endothelial growth factor, vascular endothelial growth factor type $\mathrm{C}$, and nm23 expression at primary sites were also immunohistochemically studied.

Results: In total, 35 patients (29\%) had cytokeratin-positive cells in lymph nodes. Increased expression of vascular endothelial growth factor $(P=$ $.0001)$ and vascular endothelial growth factor type $\mathrm{C}(P<.0001)$ at primary sites were significantly associated with nodal microdissemination, and nm23 was inversely correlated with microdissemination $(P=.008)$. The 3 - and 5year survivals for the patients with nodal microdissemination were $57 \%$ and $54 \%$, respectively, which was a significantly worse prognosis as compared with those prognoses $(83 \%$ and $76 \%$ ) for the patients without nodal microdissemination $(P=.006)$. The independent prognostic impact of nodal microdissemination was not clear; however, vascular endothelial growth factor retained independent significance.

Conclusion: All of these findings lead us to conclude that the microspread of tumor cells in nodes detected by immunohistochemical anticytokeratin staining is definitely a metastasis with a high risk of systemic disease. (J Thorac Cardiovasc Surg 2000;119:804-13)
W ith the technologic breakthrough for the detection of specific biologic markers for cancer cells, it has been found that tumor cells are present in some distant organs (such as lymph nodes, bone marrow, and peripheral blood circulation) in a significant proportion of various patients with cancer, including lung cancer, even if

From the First Department of Surgery, Kanazawa University School of Medicine, Takara-machi 13-1, Kanazawa 920-8641, Japan.

Supported in part by Grants-in Aid for Scientific Research (No. 08407039) from the Ministry of Education, Science and Culture, Japan.

Received for publication June 22, 1999; revisions requested Sept 17, 1999; revisions received Oct 8, 1999; accepted for publication Nov 1, 1999.

Address for reprints: Yasuhiko Ohta, MD, First Department of Surgery, Kanazawa University School of Medicine, Takara-machi 13-1, Kanazawa 920-8641, Japan (E-mail: yohta@med.kanazawa-u.ac.jp).

Copyright $\odot 2000$ by The American Association for Thoracic Surgery.

$0022-5223 / 2000 \$ 12.00+0 \quad \mathbf{1 2 / 1 / 1 0 4 1 5 2}$

doi: $1067 / \mathrm{mtc} .2000 .104152$ no metastasis can be detected by conventional clinical or pathologic examinations. ${ }^{1-9}$ Importantly, some recent studies have also reported worse postoperative outcomes of such patients, with a trend toward recurrence after curative operations. ${ }^{1,6-9}$ All of these findings have made us envisage that the microscopic spread of cancer cells to various distant organs is not merely an entrapment of cancer cells but rather might be a metastasis or an ongoing premanifestation state of occult disease. It is imperative to elucidate the clinical and biologic behavior of the microdissemination of cancer cells before taking some step to improve outcomes of patients with lung cancer with a curative resection at early stages. In this study, we performed immunohistochemistry for cytokeratin fragments and examined the microdissemination of tumor cells in the lymph nodes of patients with lung cancer with resections for cure whose diseases had been diagnosed as stage I according to the conventional pathologic examination. Furthermore, for the possible molecular markers that may pertain to the 
Table I. Clinical findings of the 122 patients with lung cancer in stage I

\begin{tabular}{llll}
\hline & & \multicolumn{2}{c}{ Nodal microdissemination } \\
\cline { 3 - 4 } & Total & Positive (\%) & Negative (\%) \\
\hline $\begin{array}{l}\text { Patients (n) } \\
\text { Sex (n) }\end{array}$ & 122 & $35(29)$ & $87(71)$ \\
$\quad$ Male & & & \\
$\quad$ Female & 78 & 22 & 56 \\
Mean age (y) & 44 & 13 & 31 \\
$\begin{array}{l}\text { Histologic features (n) } \\
\text { Adenocarcinoma }\end{array}$ & $65.2 \pm 8.2$ & $65.5 \pm 8.8$ & $65.1 \pm 8.0$ \\
$\quad$ Squamous cell & 77 & $20(26)$ & $57(74)$ \\
$\quad$ carcinoma & 37 & $14(37)$ & $23(62)$ \\
$\quad$ Adenosquamous & 6 & 0 & $6(100)$ \\
$\quad$ carcinoma & & & \\
$\quad \begin{array}{l}\text { Others } \\
\text { T factor (n) }\end{array}$ & 2 & $1(50)$ & $1(50)$ \\
T1 & & & \\
T2 & 78 & $20(26)$ & $58(74)$ \\
\hline
\end{tabular}

development of nodal microdissemination, we also examined the expression of vascular endothelial growth factor (VEGF), VEGF type C (VEGF-C), and nm23 in primary tumor cells.

\section{Patients and methods}

Patients. Both primary tumor and lymph node samples (2030 nodes) were obtained from 122 patients with primary lung cancer in stage I who received curative operations with routine systematic nodal dissection of both the hilar and the mediastinal lymph nodes as previously described ${ }^{10,11}$ in Kanazawa University Hospital from 1988 to 1991. The pathologic stage was classified according to the Japanese Lung Cancer Society classification. The 78 men and 44 women had a mean age of $65 \pm 8.2$ years (range, $46-84$ years). The pathologic types were 77 adenocarcinomas, 37 squamous cell carcinomas, 6 adenosquamous carcinomas, 1 large cell carcinoma, and 1 mucoepidermoid carcinoma. According to TNM classification, 78 patients had stage T1 N0 M0 disease and 44 patients, T2 N0 M0 disease. The basic clinical features of the patients are summarized in Table I.

Immunohistochemistry for the detection of nodal microdissemination of cancer cells. To examine the microdissemination of cancer cells in lymph nodes, we performed an immunohistochemical staining using a anticytokeratin antibody, AE1/AE3 (Dako Corporation, Carpinteria, Calif). After reviewing the hematoxylin and eosin-stained slides of the primary tumors, we used invasive edge sections for the paraffin-embedded tissues. For the paraffin-embedded lymph node samples, we also reviewed the hematoxylin and eosin-stained sections and confirmed that there was no detectable nodal metastasis. The consecutive paraffin- embedded lymph node and primary tumor tissue samples were sectioned into $4 \mu \mathrm{m}$ and were floated onto silanized slides. Then the paraffin was removed from the sections with xylene, and the sections were dehydrated with $98 \%$ ethyl alcohol at $37^{\circ} \mathrm{C}$. All tissue sections were boiled for 5 minutes in a $0.01 \mathrm{mmol}$ sodium citrate solution $(\mathrm{pH} 6.0)$ in a microwave oven 3 times and cooled and washed in phosphate-buffered saline solution (PBS). Endogenous peroxidase was blocked by treatment with $0.3 \%$ hydrogen peroxide in methanol for 15 minutes, and specimens were washed with PBS. These sections were incubated with normal goat serum diluted 10-fold with PBS for 15 minutes at room temperature for blocking. After being washed with PBS, the sections were reacted with anti-AE1/AE3 antibody (diluted 50 -fold with PBS) for 1 hour at room temperature. They were then washed with PBS and reacted with biotin-labeled goat anti-mouse immunoglobulin (Dako) for 2 hours. After they were washed with PBS, avidin-biotin-peroxidase complex was added and color was developed by 3-3' diaminobenzidine (Sigma Chemical Company, St Louis, Mo) with $0.03 \%$ hydrogen peroxide. Counterstaining was done with hematoxylin and eosin. The negative control used all reagents except for the primary antibody. Taken into consideration together (the morphologic features such as nuclear size, the nucleus-cytoplasmic ratio, and nucleolation), cells that reacted with anticytokeratin antibody were considered positive. The evaluation of the positivity was determined by two independent viewers (Y.O. and H.N.) without knowledge of the clinicopathologic factors.

In the few cases with discrepant evaluation, re-evaluation was done on a second occasion after a consultation with the other viewer, and agreement was reached.

Immunohistochemical assessment of biologic markers, VEGF, VEGF-C, and $\mathbf{n m} \mathbf{2 3}$, in primary sites. We used consecutive paraffin sections of the invasive edge of the primary tumors that were used for anticytokeratin staining and stained immunohistochemically by the labeled streptavidinbiotin method as described earlier.

The primary antibodies that were used were the anti-VEGF polyclonal antibody (Santa Cruz Biotechnology Inc, Heidelberg, Germany) diluted 100-fold, the anti-VEGF-C polyclonal antibody (Santa Cruz Biotechnology Inc) diluted 100-fold, and the anti-nm23 monoclonal antibody (Dako) diluted 50-fold. They were reacted for 2 hours at room temperature. The second antibodies used were the biotin-labeled goat anti-mouse immunoglobulin (Dako) for VEGF and nm23 and biotin-labeled rabbit anti-goat immunoglobulin (Dako) diluted 500-fold for VEGF-C.

For the assessment of VEGF-C staining, it was considered positive staining when more than $10 \%$ of the tumor area was stained. The immunoreactivities for VEGF were graded as $(-),(+)$, and $(++)$, according to the staining intensity of the tumor cells: (-) represents zero or less than $10 \%$ of positive staining area, (+) represents $10 \%$ to $50 \%$ of positive staining area, and (++) represents the strongest stain of more than $50 \%$ of positive staining area. In this study, we defined a 


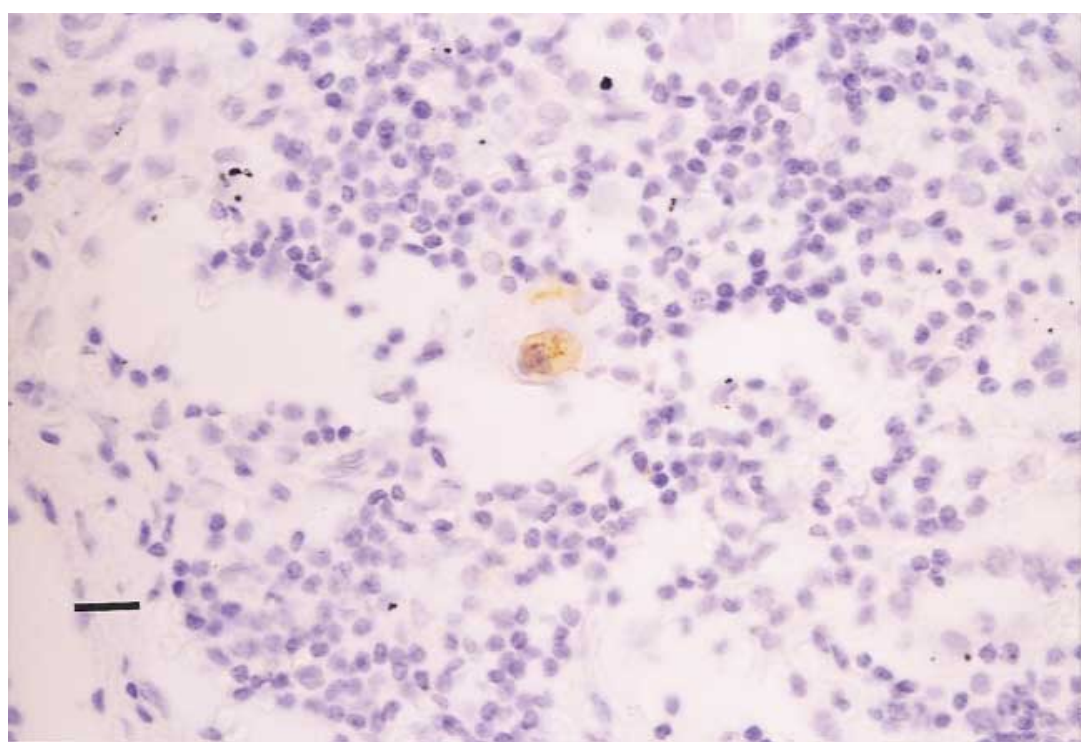

Fig 1. Photomicrographs of the consecutive sections of the lymph node with microspread of cytokeratin positive cells. Immunohistochemical staining was done using anti-AE1/AE3 antibody. Scale bar indicates $20 \mu \mathrm{m}$. (Original magnification, $\times$ 400.)

tumor with the strongest stain as VEGF overexpressing. ${ }^{12}$ For the assessment of nm 23 protein expression, tumors were considered positive if all the epithelial cells in the lesion showed cytoplasmic staining. If any of the epithelial cells were unstained, they were considered negative. ${ }^{13}$

Statistics. The association between other different variables was analyzed by the $\chi^{2}$ test. Nodal microdissemination, age ( $\geq 66$ vs $<66$ years), sex, T-factor, blood vessel invasion, lymphatic vessel invasion, pathologic types (adenocarcinoma vs squamous cell carcinoma), VEGF (strongest stain vs others), VEGF-C (positive vs negative), and nm23 (positive vs negative) were included in the assessment of prognostic indicators. Age was classified as high or low relative to the median value in total patients in the group. Survival curves were obtained by the Kaplan-Meier method and were compared univariately by the log-rank test. Both univariate and multivariate analyses were performed with the Cox proportional hazard model. The mean values were shown with \pm standard deviation.

\section{Results}

The detection of cytokeratin positive cells in lymph nodes. A strong staining for AE1/AE3 was found in all normal epithelial cells and tumor cells in primary sites despite pathologic types. In total, among 122 patients with stage I lung cancer, 35 patients (29\%) had microdissemination of tumor cells within the lymph nodes. As to the number of lymph nodes, 102 of 2030 nodes $(5 \%)$ had cytokeratin positive cells that were mainly identified at the edge portion of the nodes (Fig 1) and sometimes located in vessels within the nodes. If stratified by pathologic types, the percentage of the patients with microscopic spread of tumor cells was $26 \%$ (20/77 patients) in adenocarcinoma and 38\% (14/37 patients) in squamous cell carcinoma. There were no significant differences in the percentage of the patients with or without nodal microdissemination of cancer cells according to age, sex, pathologic types (adenocarcinoma vs squamous cell carcinoma), and $\mathrm{T}$ factor (T1 vs T2; Table I).

Nodal microdissemination and vessel invasion. From the pathologic point of view in primary sites, the percentage of tumors with lymphatic vessel invasion (60\%) tended to be higher in patients with nodal microdissemination compared with those patients without nodal microdissemination $(39.5 \% ; P=.05)$. The association between nodal microdissemination and blood vessel invasion was no higher than expected by chance (53.3\% for positive microdissemination group and $42.0 \%$ for negative microdissemination group; $P=.3$ ).

The expression of VEGF, VEGF-C, and $\mathbf{n m} 23$ in primary sites, and their association with nodal microdissemination of cancer cells. VEGF and VEGF-C antigens were mainly identified in the cytoplasm of tumor cells and the endothelial cells of vessels. Nm23 staining was found in the epithelial component and was mainly cytoplasmic in tumor cells. The examples of staining in tumor cells are shown in Fig 2. The overall expression rates of VEGF and VEGF-C were $80.3 \%$ (98/122 patients) and $45.1 \%$ (55/122 patients), respectively. Although VEGF antigen was 

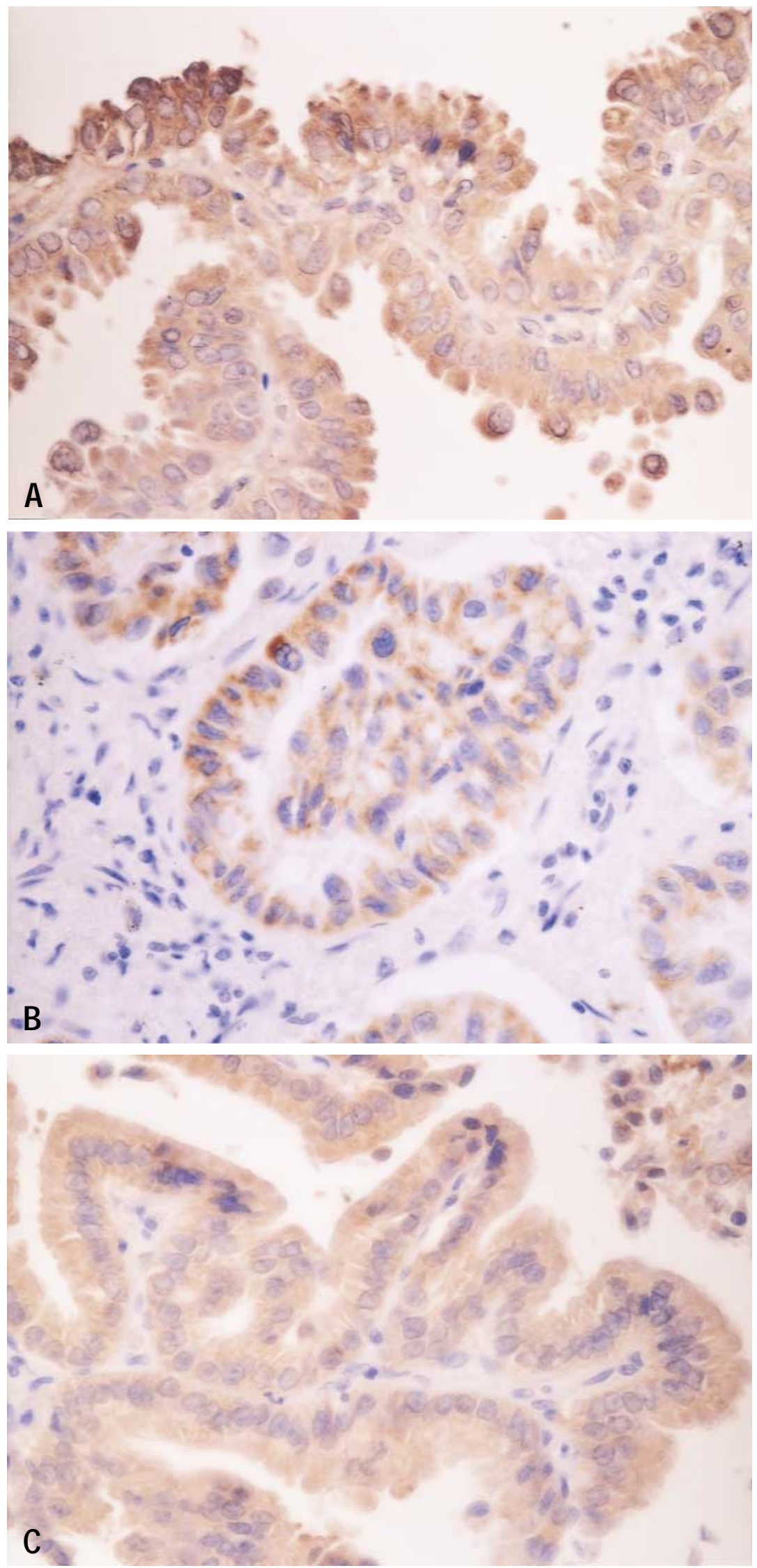

Fig 2. Immunohistochemical staining for VEGF (A), VEGF-C (B), and nm23 (C). VEGF and VEGF-C antigens were mainly identified in the cytoplasm of tumor cells in addition to the endothelial cells of vessels. Nm23 staining was found in the epithelial component and was mainly cytoplasmic in tumor cells. (Original magnifications, $\times 400$.) 


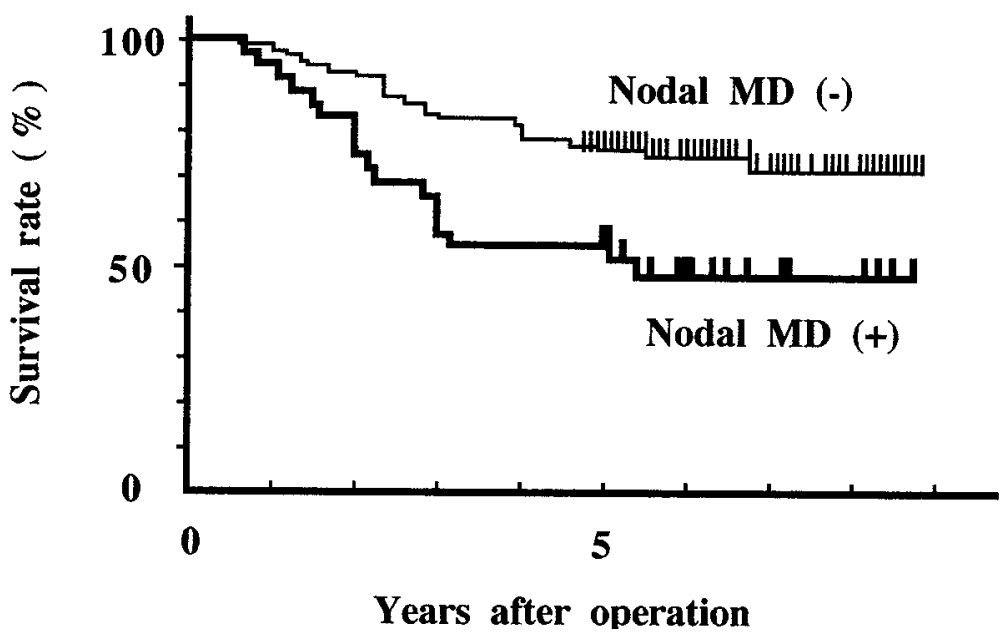

Fig 3. Kaplan-Meier survival plots for stage I lung cancers subdivided according to the nodal microspread (MD) of cytokeratin positive cells. The difference in survival between the positive nodal microspread group ( $\mathrm{n}=35$ patients) and negative nodal microspread group $(\mathrm{n}=87$ patients $)$ was significant $(P=.006)$.

Table II. VEGF, VEGF-C, and nm23 expression in tumors

\begin{tabular}{|c|c|c|c|c|c|c|c|c|}
\hline \multirow[b]{2}{*}{$\begin{array}{l}\text { Nodal } \\
\text { microdissemination }\end{array}$} & \multicolumn{4}{|c|}{ VEGF expression } & \multicolumn{2}{|c|}{$V E G F-C$ expression } & \multicolumn{2}{|c|}{ nm23 expression } \\
\hline & $\begin{array}{c}\text { Positive stain } \\
\text { (\%) }\end{array}$ & $\mathrm{P}$ value & $\begin{array}{c}\text { Strongest stain }{ }^{\dagger} \\
(\%)\end{array}$ & $\mathrm{P}$ value & $\begin{array}{c}\text { Positive stain } \\
\text { (\%) }\end{array}$ & $\mathrm{P}$ value & $\begin{array}{c}\text { Positive stain } \\
\text { (\%) }\end{array}$ & $\mathrm{P}$ value \\
\hline Positive & 89 & .15 & 69 ! & .0001 & 74 & $<.0001$ & 20 & .008 \\
\hline Negative & 77 & & $31\}$ & & $33\}$ & & $46\}$ & \\
\hline TOTAL & 80 & & 42 & & 45 & & 38 & \\
\hline
\end{tabular}

Note: The association between different variables was analyzed by the $\chi^{2}$ test.

$* 10 \%$ of positive staining area in tumor cells.

$>50 \%$ of positive staining area in tumor cells.

$\stackrel{\$}{>} 10 \%$ of positive staining area in tumor cells.

$\S^{\circledR}$ Defined as positive if all the epithelial cells in tumors showed diffuse cytoplasmic staining.

detected in large amounts in both tumor groups, those with nodal microdissemination $(88.6 \%)$ and those without microdissemination $(77.0 \% ; P=.15)$, the percentage of patients with the strongest VEGF stain were $68.6 \%$ (24/35 patients) in tumors with nodal microdissemination and only $31.0 \%$ (27/87 patients) in those patients without nodal microdissemination $(P=.0001)$. The percentage of VEGF-C-positive tumors with nodal microdissemination $(74.3 \%)$ was significantly higher than that without it $(33.3 \% ; P<.0001)$. On the other hand, nm23 expression was inversely correlated with nodal microdissemination $(P=.008)$. Table II gives an overview of the results.

Univariate and multivariate analyses of clinicopathologic and biologic characteristics. The 3- and 5 -year survivals for the patients with nodal microdissemination ( $\mathrm{n}=35$ patients) were $57.1 \%$ and $54.3 \%$, respectively, having a significantly worse prognosis as compared with those for the patients without nodal microdissemination $(\mathrm{n}=87$ patients; $82.8 \%$ and $75.9 \%$, respectively; $P=.006$; Fig 3 ). In univariate analysis, older age $(P=.03)$, T2 factor $(P<.0001)$, lymphatic vessel invasion $(P=.003)$, blood vessel invasion $(P=.005)$, overexpression of VEGF $(P=.0015)$, and $\mathrm{nm} 23$ negativity $(P=.0007)$ were significantly associated with poor survival, besides the nodal microdissemination. Among various clinical parameters, sex (male) also tended to be relevant to poor survival $(P=.05$; Table III). As a result of multivariate analysis, VEGF expression and the $\mathrm{T}$ factor were characteristics that retained a significant independent prognostic impact on overall survivals (Table IV).

If stratified by nodal status, the results of univariate analysis showed that VEGF $(P=.034), \mathrm{nm} 23(P=.048)$, and $\mathrm{T}$ factor $(P=.029)$ were significant prognostic indicators in the positive nodal microdissemination group (n = 35 patients; Table III). VEGF remained a significant independent prognostic indicator in the group of patients 
Table III. Prognostic impact of clinicopathologic and biologic factors on overall survival (univariate analysis)

\begin{tabular}{|c|c|c|c|c|c|c|}
\hline \multirow[b]{3}{*}{ Factors } & \multirow{2}{*}{\multicolumn{2}{|c|}{ Total }} & \multicolumn{4}{|c|}{ Nodal microdissemination } \\
\hline & & & \multicolumn{2}{|c|}{ Positive $(n=35)$} & \multicolumn{2}{|c|}{ Negative $(n=87)$} \\
\hline & $\mathrm{P}$ value & $\begin{array}{l}\text { Hazard ratio } \\
(95 \% \mathrm{CI})\end{array}$ & $\mathrm{P}$ value & $\begin{array}{l}\text { Hazard ratio } \\
\quad(95 \% \text { CI) }\end{array}$ & $\mathrm{P}$ value & $\begin{array}{l}\text { Hazard ratio } \\
(95 \% \text { CI })\end{array}$ \\
\hline Age $(\geq 66$ vs $<66$ y) & .03 & $1.94(1.03-3.6)$ & .09 & $2.3(0.85-6.1)$ & .2 & $1.66(0.73-3.8)$ \\
\hline Sex (male vs female) & .05 & $1.98(0.97-4.0)$ & .5 & $1.43(0.54-3.8)$ & .04 & $2.9(1.00-8.7)$ \\
\hline $\begin{array}{l}\text { Pathologic type } \\
\text { (adeno vs squamous) }\end{array}$ & .6 & $0.78(0.39-1.55)$ & .6 & $0.78(0.30-1.98)$ & .98 & $0.99(0.35-2.8)$ \\
\hline $\mathrm{T}$ factor (T1 vs $\mathrm{T} 2$ ) & $<.0001$ & $3.9(2.0-7.4)$ & .03 & $2.7(1.06-7.1)$ & .0001 & $4.6(1.95-10.9)$ \\
\hline $\begin{array}{l}\text { Lymphatic vessel invasion } \\
\text { (positive vs negative) }\end{array}$ & .003 & $2.6(1.35-5.2)$ & 6 & $1.3(0.47-3.59)$ & .004 & $3.5(1.41-8.71)$ \\
\hline $\begin{array}{l}\text { Blood vessel invasion } \\
\text { (positive vs negative) }\end{array}$ & .005 & $2.1(0.49-9.3)$ & .3 & $1.7(0.62-4.68)$ & .01 & $2.92(1.24-6.89)$ \\
\hline VEGF (strongest vs others) ${ }^{*}$ & .002 & $2.6(1.4-4.9)$ & .03 & $3.5(1.00-12)$ & .2 & $1.7(0.73-3.9)$ \\
\hline VEGF-C (positive vs negative) & .4 & $1.34(0.58-3.1)$ & .2 & $0.55(0.2-1.4)$ & .4 & $1.43(0.62-3.3)$ \\
\hline nm23 (positive vs negative) & .0007 & $3.7(1.64-8.4)$ & .05 & $5.9(0.78-45)$ & .03 & $2.7(1.06-6.9)$ \\
\hline $\begin{array}{l}\text { Nodal micro-dissemination } \\
\text { (positive vs negative) }\end{array}$ & .006 & $2.4(1.31-4.5)$ & & & & \\
\hline
\end{tabular}

$H R$, Hazard ratio.

*A tumor was included in VEGF high expressing group if positive staining area in tumor cells was more than $50 \%$.

Table IV. Cox proportional hazard regression analysis with 122 patients who had stage I lung cancer

\begin{tabular}{lllll}
\hline & \multicolumn{2}{c}{ Characteristics } & & \\
\cline { 2 - 4 } Factors & Unfavorable & Favorable & P value & Hazard ratio (95\% CI) \\
\hline VEGF & Strongest & Others & .02 & $2.3(1.16-4.7)$ \\
T factor & T2 & T1 & .006 & $3.3(0.1-0.7)$ \\
Nodal microdissemination & Positive & Negative & .15 & $1.69(0.83-3.47)$ \\
nm23 & Negative & Positive & .18 & $0.53(0.20-1.4)$ \\
Blood vessel invasion & Positive & Negative & .3 & $2.1(0.58-8.0)$ \\
Age (y) & $\geq 66$ & $<66$ & .7 & $0.88(0.42-1.84)$ \\
Sex & Male & Female & .8 & $1.13(0.50-2.54)$ \\
Lymphatic vessel invasion & Positive & Negative & .9 & $0.96(0.25-3.8)$ \\
\hline
\end{tabular}

*A tumor was included in VEGF high-expressing group if positive staining area in tumor cells was more than $50 \%$.

with nodal microdissemination (Table V). Among the patients with nodal microdissemination, the survival of the patients with VEGF overexpression $(n=24)$ was significantly worse than that of the patients without VEGF overexpression ( $\mathrm{n}=11, P<.05)$ (Fig 4).

The extent of lymph nodes with cytokeratin positive cells and the revised staging. Among 35 patients with nodal microdissemination, 7 patients had N1 disease and 28 patients had $\mathrm{N} 2$ disease, according to the sites of affected lymph nodes. Cytokeratin-positive tumor cells were found in 1 nodal station in 26 patients and in multiple nodes in 9 patients. Affected nodes were restricted to the regional lymph nodes in 17 patients; however, those outside the regional lymph nodes were involved in 11 patients. If the primary tumor was located in an upper lobe, cytokeratin-positive cells were mainly detected in the upper mediastinal area (12/14 patients). In patients with the primary tumor in the left lower lobe, cytokeratin-positive cells were mainly detected in the lower mediastinal area (3/4 patients). In tumors in the right lower lobe, however, the dominant affected area was the upper mediastinum (7/8 patients; Fig 5). After revised staging based on the nodal microdissemination, patients with $\mathrm{N} 1$ and $\mathrm{N} 2$ diseases showed significantly poorer survival than those with N0 $(P=.05$ and $P=.01$, respectively; Table $\mathrm{VI})$.

\section{Discussion}

The percentage of patients with positive cytokeratin cells within lymph nodes differs from study to study, partly because of the difference of the anticytokeratin antibody used. In patients with lung cancer whose disease was diagnosed as NO according to the conventional 


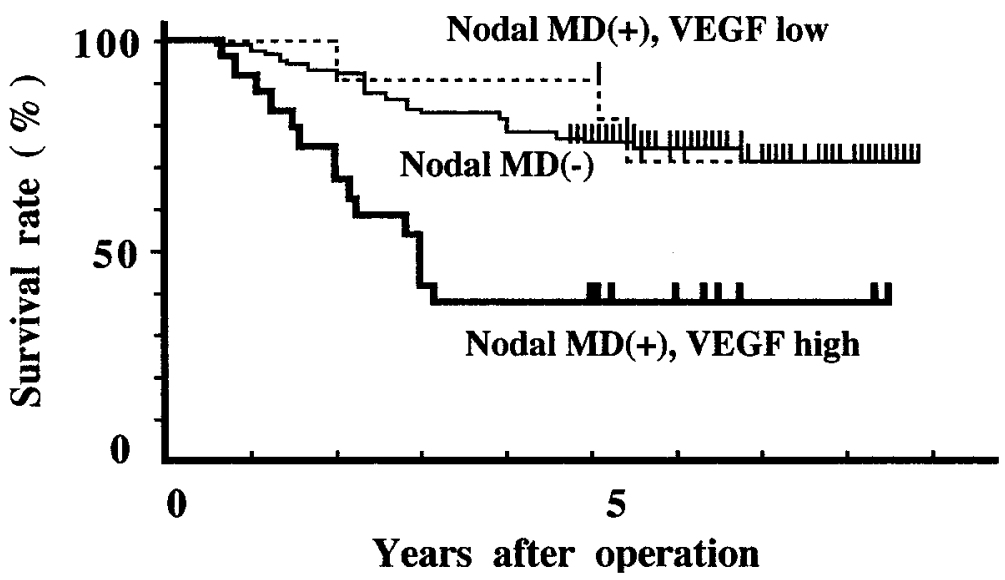

Fig 4. Kaplan-Meier survival plots for stage I lung cancers subdivided according to the nodal microdissemination $(M D)$ and VEGF expression level. A tumor was included in the VEGF high-expressing group if positive staining area in tumor cells was more than $50 \%$.

Table V. Cox proportional hazard regression analysis in patients with stage I lung cancer with or without nodal microdissemination of tumor cells

\begin{tabular}{lllll}
\hline & \multicolumn{2}{c}{ Characteristics } & & \\
\cline { 2 - 3 } & Unfavorable & Favorable & P value & Hazard ratio $(95 \%$ CI $)$ \\
\hline $\begin{array}{l}\text { Factors in positive nodal } \\
\quad \text { microdissemination group }(\mathrm{n}=35)\end{array}$ & & & & \\
VEGF* & Strongest & Others & .007 & $3.5(1.41-8.8)$ \\
T factor & T2 & T1 & .014 & $3.2(0.12-0.79)$ \\
nm23 & Negative & Positive & .69 & $1.22(0.45-3.3)$ \\
Factors in negative nodal & & & & \\
$\quad$ microdissemination group $(\mathrm{n}=87)$ & & & .02 & $3.3(1.21-9.1)$ \\
T factor & T2 & T1 & .2 & $2.2(0.62-7.6)$ \\
Sex & Male & Female & .4 & $5.18(0.157-171)$ \\
Lymphatic vessel invasion & Negative & Negative & .4 & $1.58(0.56-4.4)$ \\
nm23 & Positive & Positive & .7 & $0.51(0.016-16.5)$ \\
Blood vessel invasion & Negative & & \\
\hline
\end{tabular}

*A tumor was included in VEGF high expressing group if positive staining area in tumor cells was more than $50 \%$.

pathologic findings, a wide spectrum of the percentage of nodal microdissemination of cytokeratin-positive cells has been reported (10.4\%-70\%). ${ }^{5,9,14,15}$ The anticytokeratin antibody used in this study is a mixture of anti-AE1 monoclonal antibody that recognizes various keratins of the acidic subfamily and anti-AE3 antibody that recognizes the basic keratins of various molecular weights. Therefore it is a pan-specific cocktail of the monoclonal antibodies for human cytokeratins. As a result of using this antibody, we found that 29\% (35/122 patients) of the patients with stage I lung cancer had nodal microdissemination of cytokeratin-positive tumor cells.

In this study, we highlighted two angiogenesis-associated factors, VEGF and VEGF-C, and the metastasis associated factor, $\mathrm{nm} 23$, for the possible markers that pertain to the formation of nodal micrometastasis. As a result, we clearly found that the increased expression of VEGF and VEGF-C were significantly associated with nodal microdissemination of tumor cells together with the inhibitory expression of $n m 23$. For the connection of VEGF expression with lymph node metastasis, we previously reported that VEGF gene expression at primary sites was greater in patients with lung cancer with nodal involvement than in those patients without nodal metastasis. ${ }^{16}$ We also found that VEGF expression levels in metastatic lymph nodes themselves were conspicuously higher than those in the primary site ${ }^{16}$ Regarding VEGF function 


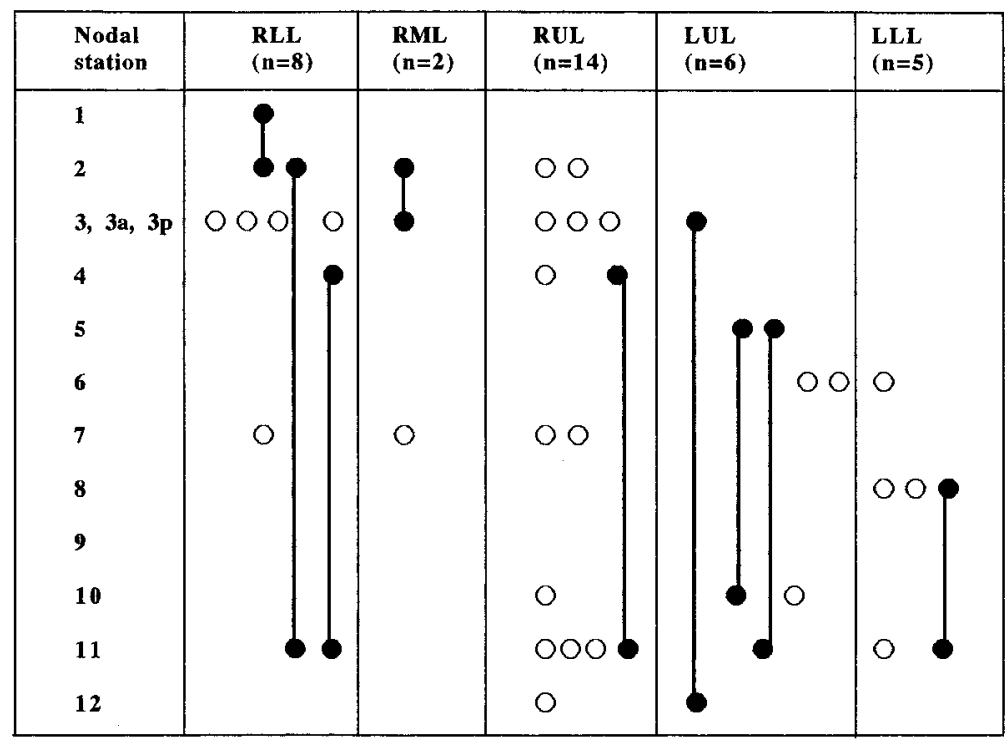

Fig 5. Intramediastinal spread of cytokeratin-positive tumor cells related on sites of the primary tumor. RLL, Right lower lobe; $R M L$, right middle lobe; $R U L$, right upper lobe; $L U L$, left upper lobe; $L L L$, left lower lobe. $\bigcirc$, Single-level metastasis; $\bigcirc$, multilevel metastasis; the bars between the closed circles signify the same cases.

Table VI. Overall survival based on the revised staging, according to the nodal microdissemination in 122 patients with stage I non-small cell lung cancer

\begin{tabular}{lccccc}
\hline & & \multicolumn{3}{c}{ Survival } \\
\cline { 2 - 6 } Revised stage & Patients $(n)$ & $3 y(95 \%$ CI) & $N$ & $5 y(95 \% C I)$ & \\
\hline Stage I (N0) ${ }^{* \dagger}$ & 87 & $83(75-91)$ & 73 & $76(67-85)$ & 65 \\
Stage II (N1) & 7 & $57(20-94)$ & 4 & $43(6-80)$ & 3 \\
Stage IIIA (N2) & 28 & $57(39-75)$ & 16 & $57(39-75)$ & 16 \\
\hline
\end{tabular}

The survival was obtained by the Kaplan-Meier method.

${ }^{*} P=.01$.

${ }^{\dagger} P=.05$ by the log-rank test.

that is different from angiogenesis, a recent report actually revealed its potential role in allowing tumor cells to avoid the host immune response. ${ }^{17}$ Furthermore, it has also been reported that the blockade of a VEGF receptor (the kinase insert domaincontaining receptor) induced suppression of cancer invasion. ${ }^{18}$ According to the results, we consider that cancer cells with high VEGF expression may elicit some function for invasion and metastasis, and another function that is different from the proliferation of endothelial cells may affect the nodal metastasis.

The function of VEGF-C also appears to extend to the lymphatic system as a ligand for fms-like tyrosine kinase 4, which was originally found in lymphatic endothelium. ${ }^{19,20}$ Although lymphangiogenesis within tumors has not yet been documented, we previously reported a significant relationship between VEGF-C expression levels and microlymphatic vessel density within resected malignant pleural tumors. ${ }^{21}$ In prostatic carcinoma, it has recently been reported that increased VEGF-C expression is associated with lymph node metastasis. ${ }^{22}$ The fundamental role of VEGF-C as a novel stimulator for vascular and/or lymphatic endothelial cells needs to be further studied to elucidate its connection with lymph node metastasis.

$\mathrm{Nm} 23$ is a putative antimetastatic gene, and its inverse correlation with lymph node metastasis has been reported by some researchers. ${ }^{23-25}$ Regarding two human $\mathrm{nm} 23$ genes $(\mathrm{nm} 23-\mathrm{H} 1$ and $-\mathrm{H} 2)$, a previous report has shown that the reduced expression of both genes was related to nodal involvement. ${ }^{23}$ In this study, we used the antibody that recognized both of the $\mathrm{nm} 23$ 
isotypes and found that the negativity of nm23 expression was associated with nodal microdissemination.

Among these three biologic markers that are associated with nodal microdissemination, VEGF and nm23 had a significant prognostic impact on overall survival. VEGF also retained a significant impact as an independent prognostic indicator together with $\mathrm{T}$ factor. As of now, several studies reported a poor outcome for patients with lung cancer with strong VEGF expression. ${ }^{26-30}$ In terms of the association of VEGF expression and relapse of the disease, we already confirmed that tumors with recurrence significantly highly expressed VEGF compared with those without recurrence in stage I patients with curative operations. ${ }^{12}$ In this study, VEGF actually remains a significant independent prognostic indicator both in the total and also in the positive nodal microdissemination group. After revised staging based on the sites of nodal microdissemination, patients with $\mathrm{N} 1$ or N2 microdissemination showed significantly worse survival than those with N0. There was not any difference in survival between $\mathrm{N} 1$ and $\mathrm{N} 2$ microdissemination, probably because of the small sample scale.

Because the presence of nodal involvement generally has a decisive meaning for the outcome of patients with lung cancer, the reason that VEGF-C did not have a significant prognostic impact is not clear. Although the VEGF-C expression was associated with nodal metastasis, the gravity of its role may not be so great as that of VEGF. Because the increased expression of VEGF is a possible link to distant metastasis through new blood vessels as a route of distant metastasis, increased VEGF expression in tumors with nodal microdissemination may also represent a high risk of systemic dissemination of cancer cells. Consistent with this concept is a previous report that demonstrated a high incidence of distant recurrence in patients with stage I non-small cell lung cancer with nodal microdissemination. ${ }^{14}$

Despite the low additional costs that will meet the practical usage, one of the disadvantageous points of this immunohistochemical method is a limitation of the examination area. Because only one cut surface of the nodes was examined in this study, the possibility of the false-negative results remains even if cytokeratinpositive tumor cells are not found. Despite the possible concomitant contamination of the false-negative cases, the pattern of nonregional skipping metastasis was similar with that we previously reported, based on the hematoxylin and eosin-stained sections. ${ }^{11}$ In the patients with primary tumor in the right lower lobe, the skipping metastases were mainly found in upper mediastinal stations $(87.5 \%)$. Especially for the tumors that are located in the right lower lobe, including the nonregional area, meticulous lymph node dissection should be needed.

In conclusion, the biologic and clinicopathologic characteristics of the nodal microdissemination appear to be valid for the concept that the presence of a small amount of cancer cells in lymph nodes detected by anticytokeratin staining is definitely a metastasis. It will be worthwhile to embark on the next step to evaluate the efficacy of selective postoperative adjuvant therapy for affected patients to inhibit the manifestation of the occult systemic disease. Although the efficacy of adjuvant chemotherapy against the nodal micrometastasis is not clear, in the patients with VEGF overexpression, antiangiogenic strategies may also be a candidate.

\section{REFERENCES}

1. Redding WH, Coombes RC, Monaghan P, Clink H, Imrie SF, Dearnaley DP, et al. Detection of micrometastases in patients with primary breast cancer. Lancet 1983;2:1271-4.

2. Lindemann F, Schlimok G, Dirschedl P, Witte J, Riethmüller G. Prognostic significance of micrometastatic tumour cells in bone marrow of colorectal cancer patients. Lancet 1992;340:685-9.

3. Moreno JG, Croce CM, Fischer R, Monne M, Vihko P, Mulholland SG, et al. Detection of hematogenous micrometastasis in patients with prostate cancer. Cancer Res 1992;52:6110-2.

4. Pantel K, Schlimok G, Braun S, Kutter D, Lindeman F, Schaller $\mathrm{G}$, et al. Differential expression of proliferation-associated molecules in individual micrometastatic carcinoma cells. J Natl Cancer Inst 1993;85:1419-24.

5. Chen Z-L, Perez S, Holmes EC, Wang H-J, Coulson WF, Wen D-R, et al. Frequency and distribution of occult micrometastases in lymph nodes of patients with non-small-cell lung carcinoma. J Natl Cancer Inst 1993;85:493-8.

6. Pantel K, Izbichi JR, Angstwurm M, Braun S, Passlick B, Karg $\mathrm{O}$, et al. Immunocytological detection of bone marrow micrometastasis in operable non-small cell lung cancer. Cancer Res 1993;53:1027-31

7. Cote RJ, Beattie EJ, Chaiwun B, Shi SR, Harvey J, Chen SC, et al. Detection of occult bone marrow micrometastases in patients with operable lung carcinoma. Ann Surg 1995;222:415-23.

8. Pantel K, Izbicki J, Passlick B, Augstwurm M, Haussinger K, Thetter $\mathrm{O}$, et al. Frequency and prognostic significance of isolated tumour cells in bone marrow of patients with non-small-cell lung cancer without overt metastases. Lancet 1996;347:649-53.

9. Izbicki JR, Passlick B, Hosch SB, Kubuschock B, Schneider C, Busch $\mathrm{C}$, et al. Mode of spread in the early phase of lymphatic metastasis in non-small-cell lung cancer: significance of nodal micrometastasis. J Thorac Cardiovasc Surg 1996;112:623-30.

10. Watanabe Y, Shimizu J, Oda M, Hayashi Y, Watanabe S, Tatsuzawa $Y$, et al. Aggressive surgical intervention in N2 nonsmall cell cancer of the lung. Ann Thorac Surg 1991;51:253-61.

11. Watanabe Y, Shimizu J, Tsubota M. Mediastinal spreads of metastatic lymph nodes in bronchogenic carcinoma. Chest 1990; 97:1059-65.

12. Ohta Y, Tomita Y, Oda M, Watanabe S, Murakami S, Watanabe Y. Tumor angiogenesis and recurrence in stage I non-small cell lung cancer. Ann Thorac Surg 1999;68:1034-8. 
13. Royds JA, Stephenson TJ, Rees RC, Shorthouse AJ, Silicocks PB. Nm23 protein expression in ductal in situ and invasive human breast carcinoma. J Natl Cancer Inst 1993;85:727-31.

14. Maruyama R, Sugio K, Mitsudomi $T$, Saitoh $G$, Ishida $T$, Sugimachi K. Relationship between early recurrence and micrometastases in the lymph nodes of patients with stage I nonsmall-cell lung cancer. J Thorac Cardiovasc Surg 1997;114:535-43.

15. Nicholson AG, Graham ANJ, Pezzella F, Angeta G, Goldstraw P, Pastorino U. Does the use of immunohistochemistry to identify micrometastases provide useful information in the staging of nodenegative non-small cell lung cancer? Lung Cancer 1997;18: 231-40.

16. Ohta Y, Watanabe Y, Murakami S, Oda M, Hayashi Y, Nonomura A, et al. Vascular endothelial growth factor and lymph node metastasis in primary lung cancer. Br J Cancer 1997;76:1041-5.

17. Gabrilovich DI, Chen HL, Girgis KR, Cunningham HT, Meny GM, Nadaf S, et al. Production of vascular endothelial growth factor by human tumors inhibits the functional maturation of dendritic cells. Nature Med 1996;2:1096-103.

18. Skobe M, Rockwell P, Goldstein N, Vosseler S, Fusenig NE. Holting angiogenesis suppresses carcinoma cell invasion. Nat Med 1997;3:1222-7.

19. Kaipainen A, Korhonen J, Mustonen T, van Hinsbergh VWM, Fang G, Dumont D, et al. Expression of the fms-like tyrosine kinase 4 gene becomes restricted to lymphatic endothelium during development. Proc Natl Acad Sci U S A 1995;92:3566-70.

20. Joukov V, Pajusola K, Kaipainen A, Chilov D, Lahtinen I, Kukk $\mathrm{E}$, et al. A novel vascular endothelial growth factor, VEGF-C, is a ligand for the Flt4 (VEGFR-3) and KDR (VEGFR-2) receptor tyrosine kinase. EMBO J 1996;15:290-8.

21. Ohta Y, Shridhar V, Bright RK, Kalemkerian GP, Du W, Carbone $\mathrm{M}$, et al. VEGF and VEGF type c play an important role in angiogenesis and lymphangiogenesis in human malignant mesothelioma tumours. Br J Cancer 1999;81:54-61.
22. Tsurusaki T, Kanda S, Sakai H, Kanetake H, Saito Y, Alitalo K, et al. Vascular endothelial growth factor-C expression in human prostatic carcinoma and its relationship to lymph node metastasis. Br J Cancer 1999;80:309-13.

23. Marone M, Scambia G, Ferrandina G, Giannitelli C, BenedettiPanici P, Iacovella S, et al. Nm23 expression in endometrial and cervical cancer: inverse correlation with lymph node involvement and myometrial invasion. Br J Cancer 1996;74:1063-8.

24. Kawakubo Y, Sato Y, Koh T, Kono H, Kameya T. Expression of $\mathrm{nm} 23$ protein in pulmonary adenocarcinomas: inverse correlation to tumor progression. Lung Cancer 1997;17:103-13.

25. Sauer T, Furu I, Beraki K, Jebsen PW, Ormerod E, Naess O. $\mathrm{Nm} 23$ protein expression in fine-needle aspirates from breast carcinoma: inverse correlation with cytologic grading, lymph node status, and ploidy. Cancer 1998;84:109-14.

26. Mattern J, Koomägi R, Volm M. Vascular endothelial growth factor expression and angiogenesis in non-small cell lung carcinomas. Int J Oncol 1995;6:1059-62.

27. Ohta Y, Endo Y, Tanaka M, Shimizu J, Oda M, Hayashi Y, et al. Significance of vascular endothelial growth factor messenger RNA expression in primary lung cancer. Clin Cancer Res 1996;2:1411-6.

28. Volm M, Koomagi R, Mattern J. Prognostic value of vascular endothelial growth factor and its receptor Flt-1 in squamous cell lung carcinoma. Int J Cancer 1997;74:64-8.

29. Fontanini G, Vignati S, Boldrini L, Chine S, Silvestri V, Lucchi $\mathrm{M}$, et al. Vascular endothelial growth factor is associated with neovascularization and influences progression of non-small cell lung carcinoma. Clin Cancer Res 1997;3:861-5.

30. Volm M, Rittgen W, Drings P. Prognostic value of ERBB-1, VEGF, cyclin A, FOS, JUN and MYC in patients with squamous cell lung carcinomas. Br J Cancer 1998;77:663-9. 